\title{
Inhibitory Effect of Nicardipine on hERG Channel
}

\author{
Eun Yong $\mathrm{CHung}^{1}$, Hea-Young $\mathrm{CHO}^{1}$, Ji-Hun $\mathrm{CHA}^{2}$, Kyoung-Jin $\mathrm{KwON}^{2}$, Seol-Hee JeON ${ }^{2}$, \\ Su Hyun $\mathrm{JO}^{3}$, Eun-Jung $\mathrm{KIm}^{2, *}$, Hye Soo KIm ${ }^{1}$, and Hye Ju $\mathrm{CHUNG}^{1, *}$ \\ ${ }^{1}$ Korea Food and Drug Administration, ${ }^{2}$ National Institute of Food and Drug Safety Evaluation, \\ Seoul 122-704, ${ }^{3}$ Department of Physiology and Institute of Bioscience and Biotechnology, \\ School of Medicine, Kangwon National University, Chuncheon 200-701, Republic of Korea
}

(Received July 27, 2010; Revised September 1, 2010; Accepted September 14, 2010)

\begin{abstract}
Drug-induced long QT syndrome is known to be associated with the onset of torsades de pointes $(\mathrm{TdP})$, resulting in a fatal ventricular arrhythmia. QT interval prolongation can result from blocking the human ether-a-go-go-related gene (hERG) channel, which is important for the repolarization of cardiac action potential. Nicardipine, a Ca-channel blocker and antihypertensive agent, has been reported to increase the risk of occasional serious ventricular arrhythmias. We studied the effects of nicardipine on $\mathrm{hERG} \mathrm{K}{ }^{+}$channels expressed in HEK293 cells and Xenopus oocytes. The cardiac electrophysiological effect of nicardipine was also investigated in this study. Our results revealed that nicardipine dose-dependently decreased the tail current of the hERG channel expressed in HEK293 cells with an $\mathrm{IC}_{50}$ of $0.43 \mu \mathrm{M}$. On the other hand, nicardipine did not affect $h E R G$ channel trafficking. Taken together, nicardipine inhibits the $h E R G$ channel by the mechanism of short-term channel blocking. Two S6 domain mutations, Y652A and F656A, partially attenuated (Y652A) or abolished (F656A) the hERG current blockade, suggesting that nicardipine blocks the hERG channel at the pore of the channel.
\end{abstract}

Keywords: Nicardipine, HERG, LQTS, HEK293, Xenopus oocyte

\section{INTRODUCTION}

A few blockbuster drugs such as terfenadine, an anti-histamine drug, were withdrawn from the market due to drug-induced QT prolongation (Redern et al., 2004). These cases of drug withdrawals not only caused heavy damage in the pharmaceutical industry, but also unexpected clinical adverse effects, such as sudden death in humans. Recently, testing for drug-induced QT prolongation has been mandatory during drug development in pharmaceutical companies and is required by drug regulatory authorities (Fermini and Fossa, 2003; Picard and Lacroix, 2003; Ajay et al., 2004; Finlayson et al., 2004).

Drug-induced long QT syndrome (LQTS) is known to result from blocking of $\mathrm{IKr}$, which is "delayed rectifier potassium current" (Finlayson et al., 2004). The rapid component of $\mathrm{IKr}$, which is involved in repolarization of cardiac

\section{${ }^{*}$ Corresponding authors}

Tel: +82-2-380-1803 (Kim EJ), +82-2-380-1712 (Chung HJ)

Fax: +82-2-380-6457 (Kim EJ), +82-2-359-6962 (Chung HJ)

E-mail: lucy0601@korea.kr (Kim EJ) hichung58@korea.kr (Chung HJ) action potential, and can induce polymorphic ventricular tachycardia Torsades de Pointes (TdP) and sudden death, is encoded by human ether-a-go-go-related-gene (hERG) (Roden and Spooner, 1999). The S6 domain located in the pore region of the channel has been reported as a binding site of drugs (Sanguinetti et al., 2005). In addition to this direct mechanism, an indirect mechanism for disrupting hERG protein trafficking to the cell surface membrane must also be considered in the hERG channel blocking activity of drugs (Sanguinetti et al., 2005).

Nicardipine, 2-[benzyl(methyl)amino]ethyl methyl 2,6-dimethyl-4-(3-nitrophenyl)-1,4-dihydropyridine-3,5-dicarboxylate, is an antihypertensive agent classified with the dihydropyridine derivatives, and is a potent calcium channel blocker with vasodilating properties. Nicardpine has been categorized with drugs of possible risk for Torsades de Pointes (TdP), which means drugs that may prolong the QT interval, but currently lack substantial evidence for causing torsades de pointes, by Arizona Center for Education and Research on Therapeutics (www.azcert.org).

In this study, we have investigated the direct and indirect effects of nicardipine on $\mathrm{hERG} \mathrm{K}^{+}$channels stably 
expressed in HEK293 cells and Xenopus oocytes.

\section{MATERIALS AND METHODS}

\section{Cell culture}

Stably transfected $h E R G$-expressing HEK293 cells were obtained from Dr. Choe. These cells were cultured in minimum essential medium containing $10 \%$ fetal bovine serum and $400 \mu \mathrm{g} / \mathrm{ml}$ geneticin (G418) in an atmosphere of $5 \% \mathrm{CO}_{2}$ and at $37^{\circ} \mathrm{C}$.

\section{Whole cell patch-clamp recording from $h E R G$ - HEK293 cells}

hERG - HEK293 cells were collected using trypsinEDTA and were suspended and settled in a chamber filled with normal tyrode solution on an inverted microscope (Carl Zeiss, Germany). The normal tyrode solution used bath solution, consisting of $143 \mathrm{mM} \mathrm{NaCl}, 5.4 \mathrm{mM} \mathrm{KCl}, 5.0$ mM HEPES, $0.33 \mathrm{mM} \mathrm{NaH}_{2} \mathrm{PO}_{4}, 0.5 \mathrm{mM} \mathrm{MgCl}_{2}, 16.6 \mathrm{mM}$ glucose and $1.8 \mathrm{mM} \mathrm{CaCl}_{2}$ at $\mathrm{pH}$ 7.4. The internal solution consisted of $130 \mathrm{mM} \mathrm{KCl}, 1 \mathrm{mM} \mathrm{MgCl} 2,5 \mathrm{mM}$ EGTA, $5 \mathrm{mM}$ Mg-ATP and $10 \mathrm{mM} \mathrm{HEPES}$ at $\mathrm{pH}$ 7.2. All reagents were purchased from Sigma (St. Louis, MO, USA). A stock solution of nicardipine (100 mM) was prepared in DMSO and diluted in the bath solutions at suitable concentrations. The borosilicate glass electrode used for glass pipetting was made by micropuller (Narishige, Japan) and resistances of the glass pipette were $2-5 \mathrm{M} \Omega$ in the bath solution. The currents were recorded using whole-cell voltage patch-clamp techniques. The signals amplified by an amplifier (Axopatch 200B amplifier, USA), were filtered by $1 \mathrm{kHz}$ and digitized by Digidata 1322A (Axon Instruments, USA). The voltage stimuli of $+20 \mathrm{mV}$ for 4 seconds and $-50 \mathrm{mV}$ for $6 \mathrm{sec}-$ onds were processed and the changes of whole cell currents were recorded. Editor Note: In highlight above, do you mean "progressed" or "processed"? After performing the recording with vehicle control, nicardipine was applied to the $h E R G$ - HEK293 cells at various doses. The inhibitory effect of nicardipine on hERG channel was evaluated using the $50 \%$ inhibition concentration $\left(\mathrm{IC}_{50}\right)$, comparing with vehicle control.

\section{Expression of hERG in oocytes}

$h E R G$ (accession no. U04270) cRNA was synthesized by in vitro transcription from $1 \mu \mathrm{g}$ of linearized cDNA using T7 message machine kits (Ambion, Austin, TX, USA) and stored in $10 \mathrm{mM}$ Tris- $\mathrm{HCl}(\mathrm{pH} 7.4)$ at $-80^{\circ} \mathrm{C}$. The amino acid mutations were generated by polymerase chain reaction (PCR) using synthetic mutant oligonucleotide primers. The mutations Y652A and F656A were verified by se- quencing (ABI3100). Stage $\mathrm{V}-\mathrm{VI}$ oocytes were surgically removed from female Xenopus laevis (Nasco, Modesto, CA, USA) anesthetized with $0.17 \%$ tricane methanesulphonate (Sigma, St. Louis, MO, USA). Using fine forceps, the theca and follicle layers were manually removed from the oocytes, and each oocyte was then injected with $40 \mathrm{nl}$ of cRNA (0.1-0.5 $\mu \mathrm{g} / \mu \mathrm{l})$. The injected oocytes were maintained in a modified Barth's Solution. The modified Barth's Solution contained (mM): $88 \mathrm{NaCl}, 1 \mathrm{KCl}, 0.4 \mathrm{CaCl}_{2}, 0.33$ $\mathrm{Ca}\left(\mathrm{NO}_{3}\right)_{2}, 1 \mathrm{MgSO}_{4}, 2.4 \mathrm{NaHCO}_{3}, 10 \mathrm{HEPES}(\mathrm{pH} 7.4)$ and $50 \mu \mathrm{g} / \mathrm{ml}$ gentamicin sulphonate. Currents were studied two to seven days after injection.

\section{Voltage clamp recordings from oocytes}

Normal Ringer's Solution contained $96 \mathrm{mM} \mathrm{NaCl}, 2 \mathrm{mM}$ $\mathrm{KCl}, 1.8 \mathrm{mM} \mathrm{CaCl}_{2}, 1 \mathrm{mM} \mathrm{MgCl}_{2}$ and $10 \mathrm{mM}$ HEPES (pH adjusted to 7.4 with $\mathrm{NaOH}$ ). All reagents were purchased from Sigma (St. Louis, MO, USA). A stock solution of nicardipine was prepared in distilled water and added to the external solutions at suitable concentrations shortly before each experiment. Solutions were applied to oocytes by continuous perfusion of the chamber while recording. Solution exchanges were completed within three min, and the hERG currents were recorded 5 min after the solution exchange. Currents were measured at room temperature $\left(20-23^{\circ} \mathrm{C}\right)$ with a two-microelectrode voltage clamp amplifier (Warner Instruments, Hamden, CT, USA). Electrodes were filled with $3 \mathrm{M} \mathrm{KCl}$ and had a resistance of 2-4 $\mathrm{M} \Omega$ for voltage-recording electrodes and 0.6-1 $\mathrm{M} \Omega$ for current-passing electrodes. Stimulation and data acquisition were controlled with an AD-DA converter (Digidata 1200, Axon Instruments) and pCLAMP software ( $v$ 5.1, Axon Instruments).

\section{Western blot analysis}

Whole-cell lysates were prepared in lysis buffer $(50 \mathrm{Mm}$ Tris- $\mathrm{HCl}$ at $\mathrm{pH} 7.5,150 \mathrm{mM} \mathrm{NaCl}, 5 \mathrm{mM}$ EDTA, $1 \%$ Nonidet P-40 (NP-40) and 10\% glycerol) containing a protease inhibitor mini-tablet (Roche Diagnostics, Mannheim, Germany). Protein concentration was determined by the BCA (bicinchoninic acid) method (Pierce Chemical, Rockford, IL). Each $10 \mu \mathrm{g}$ protein sample was separated on SDS (sodium dodecylsulfate) polyacrylamide gels and transferred to nitrocellulose membranes. The membranes were probed with hERG (Alomone Labs, APC-062 rabbit anti-human hERG), HSP70, HSP90 and GAPDH antibody (Cell Signaling Technology, USA), and developed using ECL Plus (GE Healthcare, Piscataway, NJ). The bands were captured on a Biorad Photolmager (Biorad, USA). 


\section{Confocal microscopy}

$h E R G$ - HEK293 cells were treated with various concentrations of nicardipine for $24 \mathrm{hr}$ and were then fixed with $4 \%$ formaldehyde in PBS for $10 \mathrm{~min}$ at $37^{\circ} \mathrm{C}$. The fixed cells were permeablilized with $0.4 \%$ Triton $\mathrm{X}-100$, blocked with $1 \% \mathrm{BSA}$ for $20 \mathrm{~min}$ at $37^{\circ} \mathrm{C}$ and probed with a rabbit anti-human hERG at $4^{\circ} \mathrm{C}$. A secondary antibody, Alexa Fluor $^{\mathbb{R}} 488$ goat anti rabbit IgG (Invitrogen), was used for fluorescence. hERG fluorescence was observed by confocal microscopy (Olympus IX71, Japan).

\section{Statistics}

Data were expressed as mean \pm S.E.M. The Student's $t$-test was used to calculate the statistical significance of the differences between pairs of populations. Values of $p$ $<0.05$ were considered statistically significant.

\section{RESULTS}

\section{Direct inhibitory effect of nicardipine on the hERG channel}

The effect of nicardipine on the hERG channel was evaluated in hERG-HEK293 cells, at $36^{\circ} \mathrm{C}$, using whole-cell patch clamp methods (Hamill et al., 1981; Trudeau et al., 1995) (Fig. 1). The cells were treated with various concentrations of nicardipine ranging from $0.01 \mu \mathrm{M}$ to $30 \mu \mathrm{M}$. Nicardipine inhibited the $h E R G$ currents, $I_{\text {tail }}$ and $I_{\text {steady-state, }}$ in a dose-dependent manner. Each $\mathrm{IC}_{50}$ value of $\mathrm{I}_{\text {tail }}$ and $I_{\text {steady-state }}$ was $0.43 \mu \mathrm{M}$ and $1.34 \mu \mathrm{M}$, respectively $(\mathrm{n}=3)$. The treatment with $3 \mu \mathrm{M}$ nicardipine showed an inhibitory effect of $88.8 \%$ on the hERG channel. Therefore, nicardipine appears to have a strong direct inhibitory-effect on the hERG channel.

\section{Nicardipine block of WT and mutant hERG channels expressed in oocytes}

The potencies of a channel block for the wild type and two mutant hERG channels (Y652A and F656A) were compared in order to determine if these key residues are also important in the nicardipine-induced blocking of the $\mathrm{hERG}$ channel. The effect of nicardipine on WT was quantified during to $-140 \mathrm{mV}$ after a $4 \mathrm{~s}$ activating pulses to 0 $\mathrm{mV}$ (Fig. 2). As shown in Fig. 2, the inhibitory effect of nicardipine $(20 \mu \mathrm{M})$ was partially attenuated by a Y652A mutation (panel A, B) or abolished by a F656A mutation (panel $A, C)$. The wild type $h E R G$ channel current was blocked by nicardipine with an $\mathrm{IC}_{50}$ of $15.8 \pm 2.1 \mu \mathrm{M}$ ( $\mathrm{n}=$ $5-9)$, while the $\mathrm{IC}_{50}$ values were $41.9 \pm 6.3 \mu \mathrm{M}(\mathrm{n}=4-5)$, and $850.3 \pm 4.44 \mu \mathrm{M}(\mathrm{n}=6)$ for the Y652A and F656A hERG mutants, respectively. This indicates that a mutation of
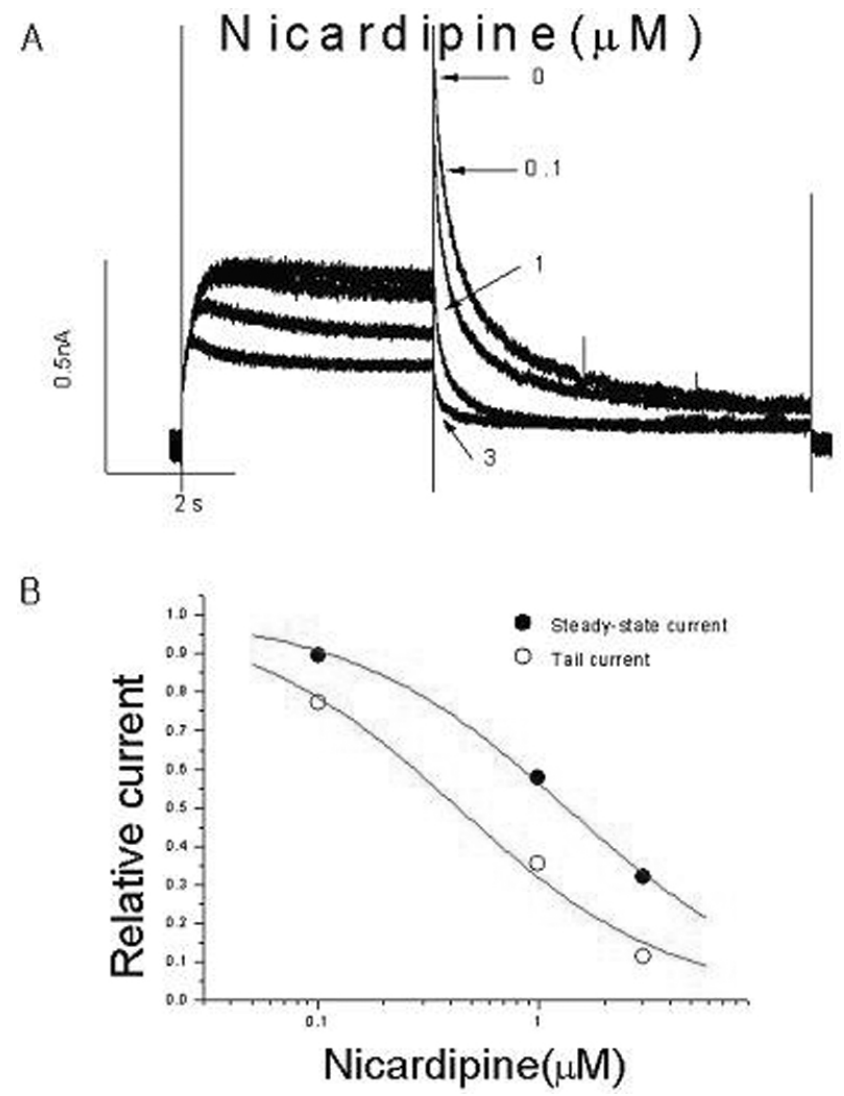

Fig. 1. Effect of nicardipine on human ether-a-go-go-related gene (HERG) channel currents expressed in hERG-HEK293 cells. Nicardipine effect was assayed with concentrations of 0.1 , 1 and $3 \mu \mathrm{M}$, including vehicle control.

Phe-656 located in the S6 domain of the hERG channel reduced the potency of the channel block by nicardipine more than a mutation of Tyr-652 in the same region.

\section{Effect of nicardipine on trafficking of hERG channel}

hERG channels consist of 2 proteins which are an immature core-glycosylated protein and a mature fully-glycosylated protein. The immature form is $135 \mathrm{kDa}$ and localized in the endoplasmic reticulum (ER), and the mature form is $155 \mathrm{kDa}$ and localized in the cell surface (Zhou et al., 1998). After being fully-glycosylated, the hERG channel can move to the cell surface while the other one remains in the ER. We investigated the effect of nicardipine on expression of hERG channel protein using western blot and immunofluorescence methods (Fig. 3, 4). The effect was evaluated by comparison with pentamidine, an antiprotozoal agent, which has been known to prolong the QT interval and inhibit hERG expression (Singh et al., 1985; Cordes et al., 2005; Kuryshev et al., 2005). Incubation with pentamidine for $24 \mathrm{hr}$ produced strong reduction of ma- 
A

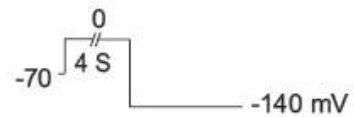

Wild Type

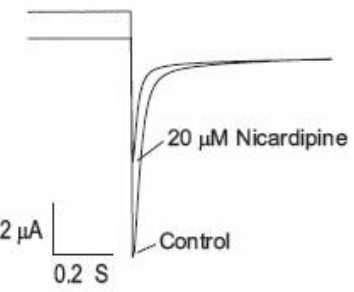

B

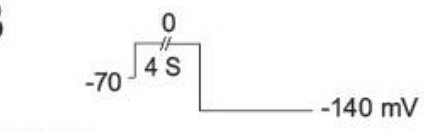

Y652A

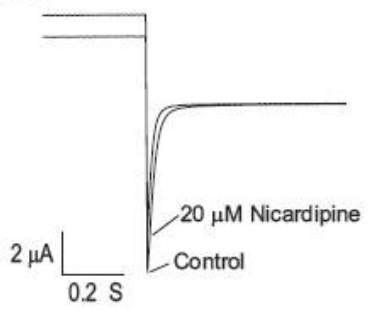

C

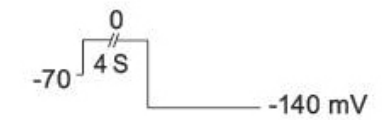

F656A
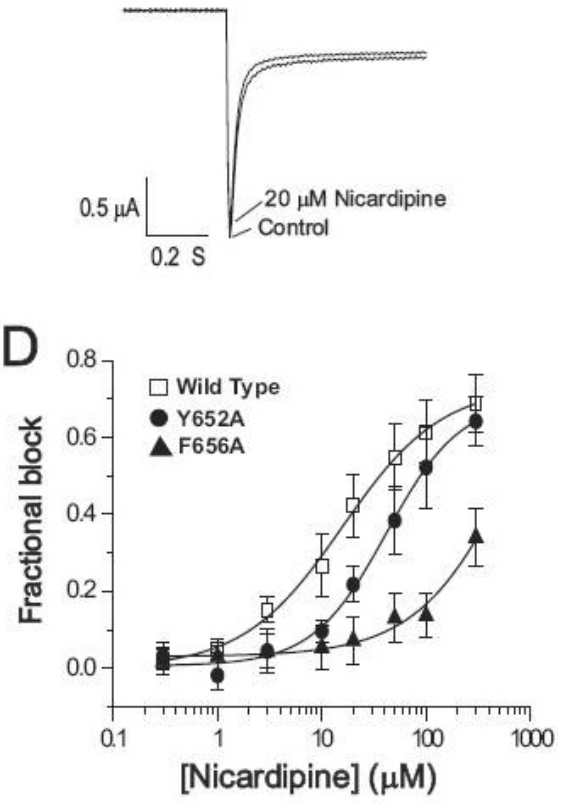

Fig. 2. Concentration-dependent inhibition of WT and mutant $h E R G$ channels expressed in oocytes. (A)-(C) Representative traces for WT and mutant hERG channel currents in the presence and absence of indicated concentrations of nicardipine. The effect of drug on WT, Y652A and F656A was quantified during to $-140 \mathrm{mV}$ after a $4 \mathrm{~s}$ activating pulses to 0 $\mathrm{mV}$. (D) The concentration-response curves were fitted with a logistic dose-response equation to obtain the $\mathrm{IC}_{50}$ values of $15.8 \pm 2.1$ $\mu \mathrm{M}, 41.9 \pm 6.3 \mu \mathrm{M}$ and $850.3 \pm 4.4 \mu \mathrm{M}$ in $\mathrm{WT}$, Y652A and F656A hERG channels, respectively. Data were expressed as mean \pm S.E.M. $(n=4-9)$. The potency of nicardipine block was reduced in the mutant channels.

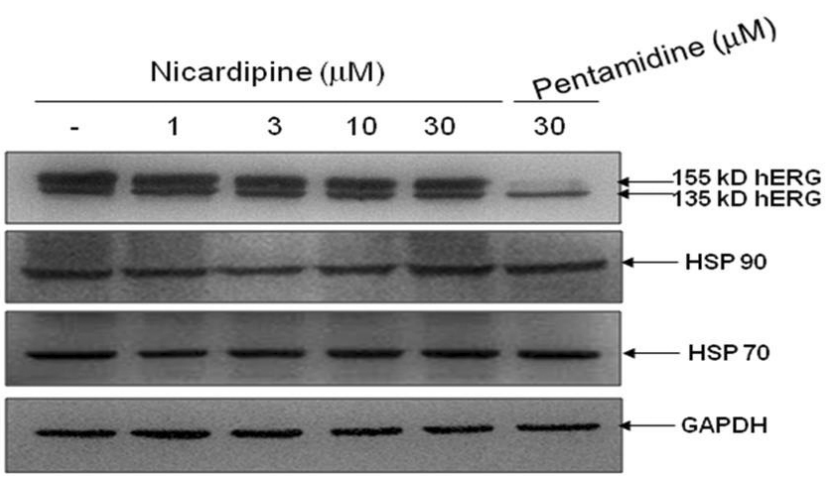

Fig. 3. Effects of nicardipine on hERG channel, Hsp70 and Hsp90 expression. Western blot data show effects of 24-hr treatment with $30 \mu \mathrm{M}$ pentamidine or $1,3,10,30 \mu \mathrm{M}$ nicardipine on hERG channel (first line), Hsp 90 (second line), and Hsp 70 (third line) protein expression comparing GAPDH protein.

ture, fully glycosylated $h E R G$ in the western blot experiment; nicardipine however, had no effect on hERG expression (Fig. 3). This result was confirmed by confocal imaging analysis (Fig. 4), where hERG channel is represented as green fluorescence, resembling a donut. The optical sections of control cells displayed a high intensity of $h E R G$ channel staining in the region of the cellular membrane, with little hERG-specific fluorescence in the cytoplasm. This image was changed by pentamidine. In the presence of $30 \mu \mathrm{M}$ of pentamidine, the cells appeared to display more diffused hERG fluorescence across the cytoplasm. In contrast, nicardipine did not influence the hERG-HEK293 cells. In the control group, it was known that the cytosolic chaperones - Hsp70 (heat shock protein 70) and Hsp90 (heat shock protein 90) interact with the $\mathrm{hERG}$ channel and are crucial for productive folding of the hERG channel during maturation (Dennis et al., 2007). To study the effect on cytosolic chaperones, we performed western blot analysis for Hsp70 and Hsp90 (Fig. 3). Nicardipine and pentamidine did not affect the expressions of Hsp70 or Hsp90 proteins.

\section{DISCUSSION}

QT interval can be measured from the beginning of the $Q$ wave to the end of the $T$ wave of the electrocardiogram (ECG). This is related to the duration of heart action potential and specific ion channels act on each phase of cardiac action potential. Especially, hERG delayed rectifier potassium channel plays a crucial role in cardiac action potential repolarization. hERG channel blocking is correlated with QT and action potential duration prolongation which can cause fatal ventricular arrhythmias such as TdP (De Ponti et al., 2002; Rashmi, 2002). The measurement considered as indicating QT prolongation, including hERG channel blocking, is therefore examined during pharmaceutical 

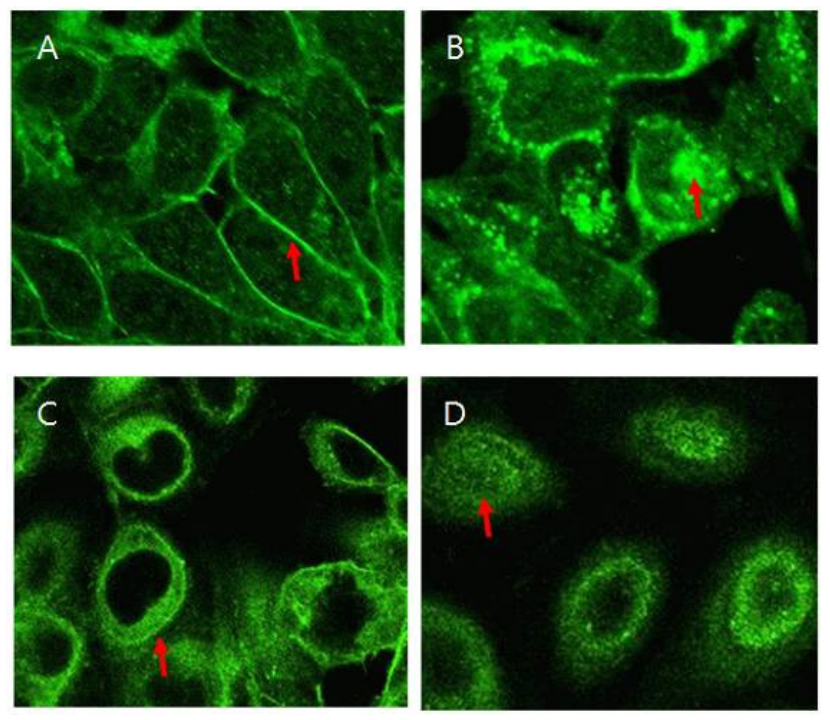

Fig. 4. Effect of nicardipine on surface membrane expression of hERG channel. After treatment with or without nicardipine or pentamidine for $24 \mathrm{hr}$, cells were examined using immunofluorescence methods. Vehicle and drug treated cells were cultured and prepared for confocal microscopy. (A) Control group, (B) 30 $\mu \mathrm{M}$ pentamidine group, (C) $30 \mu \mathrm{M}$ nicardipine group, (D) $10 \mu \mathrm{M}$ nicardipine group. A single arrow marks representative hERG protein.

drug development (Andrew and Lewis, 1995; Redfern et al., 2003). In 2004, the International Conference on Harmonization $(\mathrm{ICH})$ adopted S7B guidelines for the non-clinical evaluation of potential for delayed ventricular repolarization (QT interval prolongation) by human pharmaceuticals. S7B guidelines recommend conducting an in vitro $\mathrm{I}_{\mathrm{Kr}}$ assay for evaluation of ionic current (ICH S7A, 2000; ICH S7B, 2005).

Nicardipine has been used for treatment of hypertension and is classified as a dihydropiridine calcium channel blocker. Novel actions of calcium channel blockers have also been described, including antioxidant or anti-arterosclerosis effects. On the other hand, the potential cardiac risk of nicardipine has been noted in QT drug lists of the Arizona CERT.

In this study, we investigated the direct and indirect inhibitory effects of nicardipine on the hERG channel. In hERG assays using whole cell patch clamp techniques in hERG-HEK293 cells, nicardipine reduced $I_{h E R G}$ in a dose-dependent manner with an $\mathrm{IC}_{50}$ value of $0.43 \mu \mathrm{M}$. Y656 and F656 residues in the S6 domain of the hERG channel are important for drug binding. For determining if 2 aromatic residues of S6 domain were key residues in the nicardipine-induced blocking of the hERG channel, alanine site mutants of Y652 and F656 were constructed. These mutations of $\mathrm{Y} 652$ and $\mathrm{F} 656$ significantly reduced the blocking effect of nicardipine. Especially, a S6 mutation of Phe-656 produced a 54-fold increase of $\mathrm{IC}_{50}$, indicating the Phe-656 residue is one of the molecular determinants in channel binding for nicardipine.

We also studied whether nicardipine inhibited hERG channel trafficking to the cell surface, and examined the effects of nicardipine on expression of the hERG channel by western blot assay. Nicardipine did not affect hERG channel expression, while pentamidine, which is known to disrupt hERG channel protein trafficking, showed an inhibitory effect on the mature form (155 kDa) expression of the hERG channel. This result was confirmed with a confocal microscopy study. Additionally, the effects on the cytosolic chaperones Hsp70 and Hsp 90 were evaluated in a western blot assay. Previous studies using the leukaemia drug and Hsp inhibitor - arsenic trioxide, have shown that these cytosolic chaperones are involved with hERG channel trafficking (Ficker et al., 2003). Neither nicardipine or pentamidine influenced Hsp 70 or Hsp 90 protein expression.

In summary, the present study suggests that nicardipine inhibits the hERG channel via a direct mechanism, and not via an indirect mechanism. Additionally, the Phe656 aromatic residue is important for functioning of the drug binding site in the S6 domain. Further study is necessary for confirming the QT prolongation liability of nicardipine. However, it is known that hERG channel blocking is not perfectly correlated with QT interval, APD prolongation or TdP.

\section{ACKNOWLEDGMENTS}

This study was supported by a grant (08171KFDA462) from the Korea Food \& Drug Administration in 2008.

We thank Dr. Choe for providing the HERG-expressing HEK293 stable cell line.

\section{REFERENCES}

Ajay, J., Tara, D., Yogesh, V., Changcong, C. and Yan, G. X. (2004). Preclinical strategies to assess QT liability and torsadogenic potential of new drugs: the role of experimental models. J. Electrocardiol. 37, 7-14.

Andrew, T. S. and Lewis, B. K. (1995). Status of safety pharmacology in the pharmaceutical industry-1995. Drug Develop. Research 35, 166-172.

Cordes, J. S., Sun, Z., Lloyd, D. B., Bradley, J. A., Opsahl, A. C., Tengowski, M. W., Chen, X. and Zhou, J. (2005). Pentamidine reduces hERG expression to prolong the QT interval. Br. J. Pharmacol. 145, 15-23.

De Ponti, F., Poluzzi, E., Vaccheri, A., Bergman, U., Bjerrum, L., 
Ferguson, J., Frenz, K. J., McManus, P., Schubert, I., Selke, G., Terzis-Vaslamatzis, G. and Montanaro, N. (2002). Nonantiarrhythmic drugs prolonging the QT interval: considerable use in seven countries. Br. J. Clin. Pharmacol. 54, 171-177.

Dennis, A., Wang, L., Wan, X. and Ficker, E. (2007). hERG channel trafficking: novel targets in drug-induced long QT syndrome. Biochem. Soc. Transactions 35, 1060-1063.

Fermini, B. and Fossa, A. A. (2003). The impact of drug-induced QT interval prolongation on drug discovery and development. Nature Rev. 2, 439-447.

Ficker, E., Dennis, A. T., Wang, L. and Brown, A. M. (2003). Role of the cytosolic chaperones Hsp70 and Hsp90 in maturation of the cardiac potassium channel HERG. Circ. Res. 92, e87-100.

Finlayson, K., Witchel, H. J., McCulloch, J. and Sharkey, J. (2004). Acquired QT interval prolongation and hERG: implications for drug discovery and development. Eur. J. Pharmacol. 500, 129-142.

Hamill, O. P., Marty, A., Neher, E., Sakmann, B. and Sigworth, F. J. (1981). Improved patch clamp techniques for highresolution current recording from cells and cell-free membrane-patches. Pflugers Arch. 391, 85-100.

ICH Harmonized Tripartite Guideline. (2000). Safety pharmacology studies for human pharmaceuticals S7A, step 4.

ICH Harmonized Tripartite Guideline. (2005). The nonclinical evaluation of the potential for delayed ventricular repolarization (QT interval prolongation) by human pharmaceuticals S7B, step 4

Kuryshev, Y. A., Ficker, E., Wang, L., Hawryluk, P., Dennis, A. T., Wible, B. A., Brown, A. M., Kang, J., Chen, X. L., Sawamura, K., Reynolds, W. and Rampe, D. (2005). Pentamidine-induced long QT syndrome and block of hERG trafficking. J. Pharmacol. Exp. Ther. 312, 316-323.

Picard, S. and Lacroix, P. (2003). QT interval prolongation and cardiac risk assessment for novel drugs. Curr. Opin.
Investig. Drugs 4, 303-308.

Rashmi, R. S. (2002). The significance of QT interval in drug development. Br. J. Clin. Pharmacol. 54, 188-202.

Redern, W. S., Carlsson, L., Davis, A. S., Lynch, W. G., Mackenzie, I., Palethorpe, S., Siegl, P. K., Strang, I., Sullivan, A. T., Wallis, R., Camm, A. J. and Hammond, T. G. (2004). Relationships between preclinical cardiac electrophysiology, clinical QT interval prolongation and torsade de pointes for a broad range of drugs : evidence for a provisional safety margin in drug development. Cardiovasc. Res. $58,32-45$.

Redfern, W. S., Carlsson, L., Davis, A. S., Lynch, W. G. MacKenzie, I., Palethorpe, S., Siegl, P. K., Strang, I., Sullivan, A. T., Wallis, R., Camm, A. J. and Hammond, T. G. (2003) Relationships between preclinical cardiac electrophysiology, clinical QT interval prolongation and torsade de pointes for a broad range of drugs: evidence for a provisional safety margin in drug development. Cardiovasc. Res. 58, 32-45.

Roden, D. M. and Spooner, P. M. (1999). Inherited long QT syndromes: a paradigm for understanding arrhythmogenesis. J. Cardiovasc. Electrophysiol. 10, 1664-1683.

Sanguinetti, M. C., Chen, J., Fernandez, D., Kamiya, K., Mitcheson, J. and Sanchez-Chapula, J. A. (2005). Physicochemical basis for binding and voltage-dependent block of hERG channels by structurally diverse drugs. Novartis Found. Symp. 266, 159-166.

Singh, B. N., Baky, S. H. and Nademanee, K. (1985). Second generation of calcium antagonists: The search for greater selectivity or versatility. Am. J. Cardiol. 55, 214B-221B.

Trudeau, M. C., Warmke, J. W., Ganetzky, B. and Robertson, G. A. (1995). hERG, a human inward rectifier in the voltage-gated Pot. channel family. Science 269, 92-95.

Zhou, Z., Gong, Q., Epstein, M. L. and January, C. T. (1998). HERG channel dysfunction in human long QT syndrome. J. Biol. Chem. 273, 21061-21066. 